\title{
Phenolic Compounds and Antioxidant Activity from Saffron (Crocus sativus L.) Petal
}

\author{
Sayed Amir Hossein Goli ${ }^{1}$, Fereshteh Mokhtari ${ }^{1} \&$ Mehdi Rahimmalek ${ }^{2}$ \\ ${ }^{1}$ Food Science Department, Agriculture College, Isfahan University of Technology, Isfahan 84156-83111, Iran \\ ${ }^{2}$ Plant Breeding Department, Agriculture College, Isfahan University of Technology, Isfahan 84156-83111, Iran \\ Correspondence: Sayed Amir Hossein Goli, Food Science Department, Agriculture College, Isfahan University \\ of Technology, Isfahan, 84156-83111, Iran. Tel: 98-311-391-3357. E-mail: amirgoli@cc.iut.ac.ir
}

Received: June 21, 2012 Accepted: July 6, 2012 Online Published: August 31, 2012

doi:10.5539/jas.v4n10p175 URL: http://dx.doi.org/10.5539/jas.v4n10p175

\begin{abstract}
Saffron petal is the main by-product of saffron processing which is producing in large amounts annually. The purposes of this work were to determine total phenolics content in the methanolic extract of saffron petal using Folin-ciocalteu reagent and to measure their antioxidant activity in various in vitro models, such as $\beta$-carotene-linoleate and 1,1-diphenyl-2-picryl hydrazyl (DPPH). Saffron petal extract in different concentrations $\left(0.5-5 \mathrm{mg} \mathrm{ml}^{-1}\right)$ were compared with standard antioxidants of ascorbic acid, $\alpha$-tocopherol and TBHQ $(0.5-1 \mathrm{mg}$ $\mathrm{ml}^{-1}$ ). Total phenolics content was $3.42 \mathrm{mg}$ gallic acid/g dry weight. In model systems of $\beta$-carotene-linoleate and $\mathrm{DPPH}$, the extract at $500 \mathrm{ppm}$ concentration showed $91.4 \%$ and $74.2 \%$ antioxidant activity which was comparable with that of TBHQ $(93.1 \%$ and $77.9 \%)$ at $100 \mathrm{ppm}$. The results showed that saffron petal could be considered as a bioresource of phenolic compounds with high antioxidant activity.
\end{abstract}

Keywords: saffron petal, phenolic, $\beta$-carotene-linoleate, DPPH

\section{Introduction}

Nowadays, synthetic antioxidants such as BHA, BHT and TBHQ are widely used in food industry. However, it is arguable whether these compounds are safe and their use in food products is questioned (Konczak, Zabaras, Dunstan \& Aguas, 2010; Kosar, Goger \& Baser, 2011). In recent years there has been an interest to determine total phenolics (as natural antioxidant) content and their antioxidant activities in various plants specifically by-products of agriculture and even marine microorganisms (Negro, Tommasi \& Miceli, 2003; Lee \& Lee, 2010; Fu et al., 2011; Goh, Yusoff \& Loh, 2010). Phenolic compounds of edible and inedible plants have multiple biological effects such as anti-inflammatory, bactericidal as well as antioxidant properties because of their ability to neutralize free radicals (Wojdylo, Oszmianski \& Czemerys, 2007; Temerdashev, Frolova \& Kolychev, 2011). Herbs are used in many industries such as medicine, food, fragrance and cosmetics. Crude extracts of herbs and spices have been reported to be rich in phenolics and attracted more attention in food industry because of their antioxidant capacity (Wojdylo et al., 2007).

Crocus sativus L. commonly known as saffron, belonging to Iridaceae family, is a perennial plant widely cultivated in different parts of the world, particularly in Iran (Esmaeili, Ebrahimzadeh, Abdi \& Safarian, 2011). Although the source of saffron is obscure, it is apparently originated from Asia Minor and Iran. The name of saffron is derived from Arabic word of za-faran meaning "be yellow" (Winterhalter \& Straubinger, 2000; Cabellero-Ortega, Pereda-Miranda \& Abdullaev, 2007). Iran is the major producer of saffron in the world market, but its quality is reported not to be as well as saffron of other main supplier, Spain (Winterhalter \& Straubinger, 2000; Cabellero-Ortega et al., 2007). Although the most usage of saffron is as a food coloring and flavoring agent in food industry, but it is utilized in folk medicine as antispasmodic, carminative, stomachic, expectorant, aphrodisiac, cardiotonic and stimulant. Modern pharmacological studies have reported that saffron extract have antitumor, anticonvulsant, antidepressant, anti-inflammatory, anti-hyperlipidemic, free radical scavenging and antioxidant effects (Hadizadeh, Khalili, Hosseinzadeh \& Khair-Aldine, 2003; Asdaq \& Inamdar, 2010; Melnyk, Wang \& Marcone, 2010). Moreover, chemopreventive and protective effects of saffron extract on genotoxins-induced oxidative stress in animals have been reported (Asdaq \& Inamdar, 2010).

Since one dry stigma in saffron plant weighs about $2 \mathrm{mg}$ and each flower contains three of them, approximately 150,000 saffron flowers must be carefully picked for the production of $1 \mathrm{~kg}$ of the spice. Harvesting the flowers 
and separating the stigmas is very time consuming. Consequently, saffron is still the world's most expensive spice (Winterhalter \& Straubinger, 2000; Melnyk et al., 2010). Saffron petal is the main by-product of saffron harvesting which is not usable for the farmers. The amount of saffron petal is more than 10000 tons each year (Kafi, Kakhki \& Karbasi, 2000). Nowadays, saffron petals are only used for dye extraction, which is not flourished yet.

There are limited reports on phenolic compounds of saffron and their antioxidant activity. Ordoudi, Befani, Nenadis, Koliakos and Tsimidou (2009) investigated antiradical capacity of saffron stigma extract and its bioactive constituents using the Folin-ciocalteu reagent and various free radical species produced in cell-free or cell model system. They concluded that saffron extracts exhibit a considerable intracellular antioxidant activity. In other study, the phenolic and flavonoid compounds of saffron stigma were determined by HPLC. The results showed that saffron stigma had antioxidant activity which was lower than that of BHT and $\alpha$-tocopherol. Total phenolics content of stigma was $6.55 \mathrm{mg}$ gallic acid equivalent/g dry weight for methanolic saffron extract (Karimi, Oskoueian, Hendra \& Jaafar, 2010). Esmaeili et al. (2011) evaluated total phenolics content in saffron corms in dormancy and waking stages. Gentisic and gallic acids were the highest and lowest phenolic compounds in dormant and waking corms, respectively. Hadizadeh et al. (2003) isolated kaempfrol from saffron petal and determined its structure by chemical and spectroscopic methods. There is only one report in which phenolic compounds of saffron petal was investigated. Termentzi and Kokkalou (2008) isolated various fractions from the petals of crocus sativus cultivated in Greece and determined its phenolics content. They also reported the content of flavonoids, acids, crocusetin and alkaloids, but in their study no reports were found about antioxidant activity of saffron petal in different model systems. However, no research has been reported on phenolics content and their antioxidant capacity of Iranian saffron petal.

The objectives of present study were (1) to determine total phenolics content of saffron petal using Folin-Ciocalteu reagent and (2) to evaluate its antioxidant activity by various model systems and 3 ) to determine the suitable concentration of saffron petal extract which is equivalent in antioxidant activity with standard antioxidants.

\section{Materials and Method}

\subsection{Chemicals}

All solvents and chemicals were analytical grade and obtained from Merck (Darmstadt, Germany). 1,1-diphenyl-2-picrylhydrazyl (DPPH) and tert-Butylhydroquinone (TBHQ) were purchased from Sigma Chemical Co. (Sigma-Aldrich, Germany).

\subsection{Plant Material}

Saffron petals were collected from Kesheh, Karkas region, Isfahan province, Iran in 2011. The petals were air-dried in shadow and ground into fine powder by a laboratory mill.

\subsection{Methanol Extract}

One gram of the fine ground sample was extracted with 10 methanol in a flask placed in an ultrasonic bath (Hilsonic, UK) at $65^{\circ} \mathrm{C}$ for $2 \mathrm{~h}$. The sample was cooled at room temperature and centrifuged (Sigma, Germany) at 1500rpm for 15min (Budrat \& Shotipruk, 2009).

\subsection{Total Phenolics Content}

The total phenolics were determined colorimetrically by means of the Folin-Ciocalteu method, as described by Pinelo, Rubilar, Sineiro and Nunez (2004). $2.5 \mathrm{ml}$ of ten-fold diluted Folin-Ciocalteu reagent, $2 \mathrm{ml}$ of $7.5 \%$ sodium carbonate, and $0.5 \mathrm{ml}$ of phenolic extract were mixed. After heating at $45^{\circ} \mathrm{C}$ for $15 \mathrm{~min}$, the absorbance was measured at $765 \mathrm{~nm}$ against a blank. The phenolics content was expressed as gallic acid equivalent/g dry weight of sample.

\subsection{Antioxidant Activity by $\beta$-carotene-linoleic Acid Method}

This assay was conducted according to method of Gursoy, Sarikurkcu, cengiz and Solak (2009) by minor modifications. $0.5 \mathrm{mg} \beta$-carotene was dissolved in $1 \mathrm{ml}$ of chloroform and $25 \mu 1$ linoleic acid and $200 \mathrm{mg}$ Tween 80 was added to prepare stock solution. The solvent was evaporated by a vacuum evaporator and $100 \mathrm{ml}$ of oxygenated distilled water was added with vigorous shaking. $2.5 \mathrm{ml}$ of reaction mixture was dispersed to test tubes and $0.5 \mathrm{ml}$ of various concentrations $\left(0.5-5 \mathrm{mg} \mathrm{ml}^{-1}\right)$ of the extract (for control antioxidants, $0.5 \mathrm{and} 1 \mathrm{mg}$ $\mathrm{ml}^{-1}$ ) was added and the mixture was incubated at $50^{\circ} \mathrm{C}$. The absorbance was measured at zero time $(\mathrm{t}=0)$ at 490 $\mathrm{nm}$. Absorbance reading was continued at an interval of $15 \mathrm{~min}$ until the color of $\beta$-carotene disappeared in the control tubes $(\mathrm{t}=120 \mathrm{~min})$. 
The antioxidant activity (AA) of the extracts was calculated using the following formula:

$$
\mathrm{AA}=100\left[1-\left(\mathrm{A}_{0}-\mathrm{A}_{\mathrm{t}}\right) /\left(\mathrm{A}_{0}^{\circ}-\mathrm{A}_{\mathrm{t}}^{\circ}\right)\right]
$$

Where $\mathrm{A}_{0}$ and $\mathrm{A}^{\circ}$ are the absorbance values measured at zero time and $\mathrm{A}_{t}$ and $\mathrm{A}_{\mathrm{t}}^{\circ}$ are the absorbance values measured after incubation of $120 \mathrm{~min}$ for test sample and control, respectively.

\subsection{Scavenging Activity on DPPH}

Different concentrations of saffron petal extract (equivalent to 50,100, 250 and $500 \mathrm{ppm}$ ) and TBHQ, ascorbic acid and $\alpha$-tocopherol (50 and $100 \mathrm{ppm}$ ) were taken in different test tubes. The volume was adjusted to $100 \mu \mathrm{L}$ by adding methanol. Five milliliters of a $0.1 \mathrm{mM}$ methanolic solution of DPPH was added to tubes and shaken vigorously. The tubes were allowed to stand at $27^{\circ} \mathrm{C}$ for $20 \mathrm{~min}$. The control was prepared without any extract, and methanol was used for the baseline correction. The absorbance of the samples was measured at $517 \mathrm{~nm}$. Radical scavenging activity of the extracts was calculated by the following formula:

$\%$ radical scavenging activity $=($ control OD - sample OD/control OD) $\times 100$ (Singh, Murthy \& Jayaprakasha, 2002).

\subsection{Reducing Power}

The extracts $(2.5 \mathrm{ml})$ were mixed with $2.5 \mathrm{ml}$ of $1 \%$ potassium ferricyanide and $2.5 \mathrm{ml}$ of $200 \mathrm{mM}$ sodium phosphate buffer ( $\mathrm{pH} \mathrm{6.6)}$ and incubated at $50^{\circ} \mathrm{C}$ for $20 \mathrm{~min}$. Then $2.5 \mathrm{ml}$ of $10 \%$ trichloroacetic acid was added and the mixture was centrifuged at $200 \mathrm{~g}$ for $10 \mathrm{~min}$. The upper layer $(2.5 \mathrm{ml})$ was mixed with $2.5 \mathrm{ml}$ of deionized water and $0.5 \mathrm{ml}$ of $0.1 \%$ ferric chloride. The absorbance at $700 \mathrm{~nm}$ was measured against a blank (Gursoy et al., 2009).

\subsection{Statistical Analysis}

The results were shown as the mean \pm SD of three separate determinations. The data were statistically analyzed by ANOVA program in Statistix 8 software. The means evaluation was done using Least Significant difference (LSD) test at a confidence level of $95 \%$. The dendrogram based on the results were constructed using SPSS ver.17.

\section{Results and Discussion}

The total phenolics content was determined using Folin-Ciocalteu reagent. The data showed that saffron petal had $3.42 \pm 0.2 \mathrm{mg}$ phenolic content equivalent to gallic acid per g dry weight. This value was higher than amount of phenolic acids (1.38 mg caffeic acid/g dry weight) reported by Termentzi and Kokkalou (2008) for saffron petal harvested in Greece.

Since there are differences between various radical scavenging systems, different in vitro model systems have been recently recommended to evaluate antioxidant capacities (Rockenbach et al., 2011). Therefore, in this study, three model systems; $\beta$-carotene/linoleic acid, DPPH and reducing power through potassium ferricyanide methods were applied. Food lipids and cell membranes in human body contain unsaturated fatty acids which are in exposure to oxidation reaction. Thus, in evaluation of antioxidant activity, the test based on unsaturated fatty acid oxidation is very important. $\beta$-carotene/linoleic acid method is widely used to investigate oxidation progress in polyunsaturated fatty acids. In this method, linoleic acid free radical formed from oxidation of fatty acid, attacks the highly unsaturated $\beta$-carotene molecules. As $\beta$-carotene loses its double bonds by oxidation development, its color also would disappear which can monitored by spectrophotometry. The presence of extracts with antioxidant activity can hinder $\beta$-carotene bleaching through neutralization of free radicals formed in the system (Kosar et al., 2011; Singh et al., 2002; Rockenbach et al., 2011).

Antioxidant effect of petal extracts as well as natural and synthetic antioxidants in model system of $\beta$-carotene/linoleic acid is presented in Table 1. For all antioxidants, an increment in activity was observed when the concentration increased ( $\mathrm{F}$ value $=838, \mathrm{P}<0.01$ ). Although TBHQ at $100 \mathrm{ppm}$ concentration showed highest antioxidant activity of \%93.07 but petal extract (PE) at $500 \mathrm{ppm}(\% 91.39)$ had no significant difference with TBHQ $(\mathrm{P}>0.05)$. This data showed that petal extract in higher concentration can be competitive with TBHQ as a standard antioxidant. PE with 250 ppm concentration (PE-250) was in second order (\%90.02) and then PE-100 and TBHQ-50 were more active antioxidants, respectively. In this method, vitamin $\mathrm{C}$ or ascorbic acid in both concentrations had the least activity which might be due to that ascorbic acid is water-soluble and cannot be efficient in reduction of fatty acid oxidation resulting in bleaching of $\beta$-carotene. Kosar et al. (2011) have reported the same results in which ascorbic acid showed the weakest antioxidant capacity compared to BHT and Salvia halophila extract due to its pro-oxidant activity. 
Table 1. Antioxidant activity of different antioxidants measured by the $\beta$-carotene/linoleic acid method

\begin{tabular}{lcccc}
\hline Samples & \multicolumn{4}{c}{$\%$ Antioxidant activity } \\
\cline { 2 - 5 } & $50 \mathrm{ppm}$ & $100 \mathrm{ppm}$ & $250 \mathrm{ppm}$ & $500 \mathrm{ppm}$ \\
\hline Ascorbic acid & $47.54 \pm 0.63^{\mathrm{h}}$ & $49.07 \pm 0.28^{\mathrm{h}}$ & - & - \\
$\alpha$-tocopherol & $60.33 \pm 1.83^{\mathrm{g}}$ & $68.62 \pm 0.33^{\mathrm{f}}$ & - & - \\
TBHQ & $80.44 \pm 0.04^{\mathrm{d}}$ & $93.07 \pm 0.02^{\mathrm{a}}$ & - & - \\
Petal extract & $78.52 \pm 0.49^{\mathrm{e}}$ & $88.49 \pm 0.75^{\mathrm{c}}$ & $90.02 \pm 1.55^{\mathrm{bc}}$ & $91.39 \pm 0.08^{\mathrm{ab}}$ \\
\hline
\end{tabular}

Lowercase letters are represented significant difference at 0.05 levels

The DPPH method is a simple, practical and sensitive assay which has been widely used to detect active antioxidants with scavenging capacity even in low concentration (Pinelo et al., 2004; Zhu, Lian, Guo, Peng \& Zhou, 2011). The ability of antioxidants to react with DPPH which is a stable free radical and its conversion to $\alpha, \alpha$-diphenyl- $\beta$-picryl hydrazine is expressed in \% DPPH inhibition. DPPH by accepting an electron loses its color and changes from purple to yellow. Discoloration degree indicates that the antioxidants possess scavenging potentials. Since DPPH is a stable free radical and does not dimerize as happens with most free radicals, the absorbance diminution depends linearly on the antioxidant concentration (Kosar et al., 2011; Singh et al., 2002; Zhu et al., 2011; Esquivel, Moreno, Álvarez, Álvarez \& Giusti, 2011).

As shown in Table 2, in this model system, as well as $\beta$-carotene method, a moderate increase in radical scavenging was observed when the concentration of all antioxidants was increased ( $F$ value $=394, \mathrm{P}<0.01$ ). TBHQ at $100 \mathrm{ppm}$ concentration with \%77.81 of radical scavenging was the most active antioxidant. The ability of DPPH scavenging was decreased in the following order; ascorbic acid-100 > TBHQ-50 > ascorbic acid -50 > PE-500, although PE-500 had no significant difference with ascorbic acid-100. Among the samples, $\alpha$-tocopherol was weak in DPPH radical scavenging (Table 2). The results were in agreement with that of Kosar et al. (2011) and Maksimovic (2008) stated that ascorbic acid along with synthetic antioxidant had the strongest activity in inhibition of DPPH.

Table 2. Radical scavenging activity of different antioxidants measured by DPPH method

\begin{tabular}{lcccc}
\hline Samples & \multicolumn{4}{c}{$\%$ Inhibition of DPPH } \\
\cline { 2 - 5 } & $50 \mathrm{ppm}$ & $100 \mathrm{ppm}$ & $250 \mathrm{ppm}$ & $500 \mathrm{ppm}$ \\
\hline Ascorbic acid & $74.90 \pm 0.71^{\mathrm{abc}}$ & $76.35 \pm 0.29^{\mathrm{ab}}$ & - & - \\
$\alpha$-tocopherol & $35.15 \pm 1.50^{\mathrm{e}}$ & $39.92 \pm 1.85^{\mathrm{d}}$ & - & - \\
TBHQ & $75.02 \pm 1.59^{\mathrm{abc}}$ & $77.81 \pm 2.14^{\mathrm{a}}$ & - & - \\
Petal extract & $22.45 \pm 2.80^{\mathrm{f}}$ & $39.80 \pm 2.89^{\mathrm{d}}$ & $72.94 \pm 1.65^{\mathrm{c}}$ & $74.23 \pm 1.82^{\mathrm{bc}}$
\end{tabular}

Lowercase letters are represented significant difference at 0.05 levels

The ability of the antioxidant fraction to reduce $\mathrm{Fe}^{+3}$ to $\mathrm{Fe}^{+2}$ represents the reducing power of the antioxidant. In this method, reducing power could be determined by color changes of the solution from yellow to various shades of green and blue (depending on the activity of the samples) which can be monitored by absorbance measurement at $700 \mathrm{~nm}$ (Kosar et al., 2011; Zhu et al., 2011). In this assay (Table 3), contrary to other methods, ascorbic acid had the highest power in reduction of $\mathrm{Fe}^{+3}(1.2)$. Then, TBHQ at 100, PE at 500 and ascorbic acid at $50 \mathrm{ppm}$ concentration had more activity $(0.92,0.72$ and 0.6 , respectively) $(\mathrm{F}$ value $=1484, \mathrm{P}<0.01)$. The lowest activity was pertained to $\alpha$-tocopherol and PE at $50 \mathrm{ppm}$. Since ascorbic acid is a strong reductive antioxidant, in this model system this compound showed higher activity followed by TBHQ and plant extract which was in agreement with data of Kosar et al. (2011) and Maksimovic (2008). 
Table 3. Reducing power of different antioxidants measured by ferricyanide method

\begin{tabular}{lcccc}
\hline Samples & \multicolumn{4}{c}{ Reducing power (absorbance at 700 nm) } \\
\cline { 2 - 5 } & $50 \mathrm{ppm}$ & $100 \mathrm{ppm}$ & $250 \mathrm{ppm}$ & $500 \mathrm{ppm}$ \\
\hline Ascorbic acid & $0.60 \pm 0.00^{\mathrm{d}}$ & $1.20 \pm 0.02^{\mathrm{a}}$ & - & - \\
$\alpha$-tocopherol & $0.02 \pm 0.00^{\mathrm{i}}$ & $0.17 \pm 0.01^{\mathrm{g}}$ & - & - \\
TBHQ & $0.41 \pm 0.03^{\mathrm{e}}$ & $0.92 \pm 0.01^{\mathrm{b}}$ & - & - \\
Petal extract & $0.10 \pm 0.00^{\mathrm{h}}$ & $0.19 \pm 0.00^{\mathrm{g}}$ & $0.30 \pm 0.00^{\mathrm{f}}$ & $0.72 \pm 0.00^{\mathrm{c}}$ \\
\hline
\end{tabular}

Lowercase letters are represented significant difference at 0.05 levels

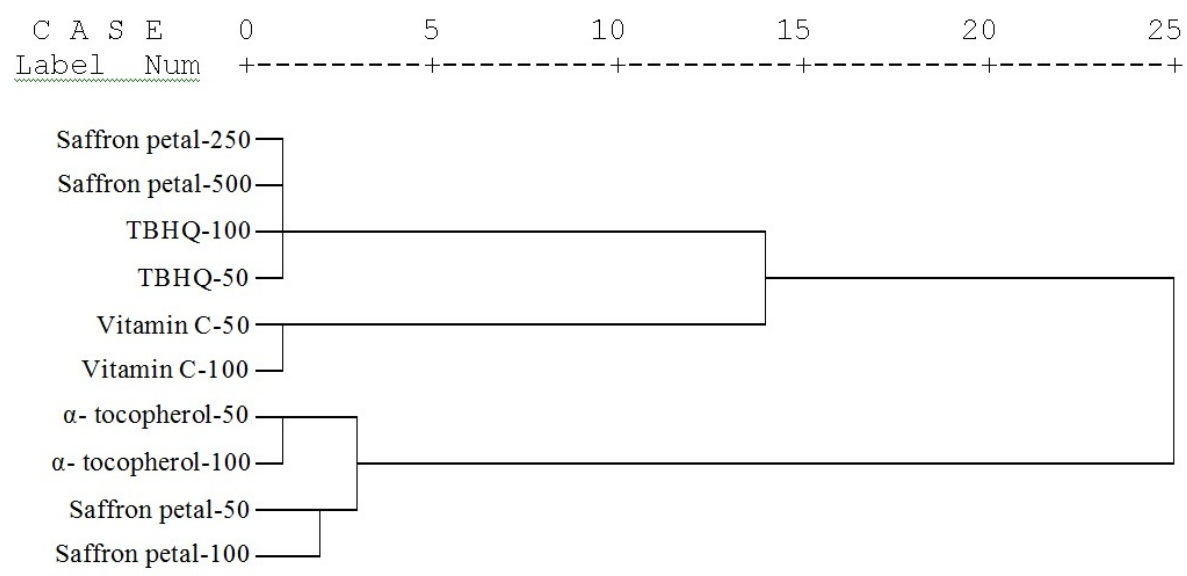

Figure 1. The dendrogram based on antioxidative activity of natural and synthetic antioxidants

To facilitate comparison of different antioxidants activity, the dendrogram constructed based on the results of three antioxidant model systems. The dendrogram classified various antioxidants tested in this research into three major groups (Figure 1). According to cluster analysis and in respect to antioxidant activity, TBHQ-50, TBHQ-100, PE-250 and PE-500 were classified in one group. Ascorbic acid was separated in different group and PE-50 and PE-100 were grouped along with $\alpha$-tocopherol. The cluster analysis confirmed the results of model systems in which ascorbic acid showed different activity, TBHQ and saffron petal extract at higher concentration ( 250 and $500 \mathrm{ppm}$ ) had high similarity in antioxidant power meanwhile other compounds had the lowest activity.

\section{Conclusion}

It could be concluded that saffron petal as the main by-product of saffron production possessed considerable phenolic compounds which showed high antioxidant power. Regarding to antioxidant activity, petal extract at $500 \mathrm{ppm}$ was comparable with TBHQ (as a strong synthetic antioxidant) at $100 \mathrm{ppm}$. Therefore, taking into account that saffron petal is discarding more than thousands tons each year, phenolic compounds extracted from this solid waste might be used as natural antioxidant.

\section{References}

Asdaq, S. M. B., \& Inamdar, M. N. (2010). Potential of crocus sativus (saffron) and its constituent, crocin, as hypolipidemic and antioxidant in rats. Applied Biochemistry and Biotechnology, 162, 358-372. http://dx.doi.org/10.1007/s12010-009-8740-7

Budrat, P., \& Shotipruk, A. (2009). Enhanced recovery of phenolic compounds from bitter melon (momordica charantia) by subcritical water extraction. Separation and Purification Technology, 66, 125-129. http://dx.doi.org/10.1016/j.seppur.2008.11.014

Caballero-Ortega, H., Pereda-Miranda, R., \& Abdullaev, F. I. (2007). HPLC quantification of major active components from 11 different saffron (crocus sativus L.) sources. Food Chemistry, 100, 1126-1131. http://dx.doi.org/10.1016/j.foodchem.2005.11.020

Esmaeili, N., Ebrahimzadeh, H., Abdi, K., \& Safarian, S. (2011). Determination of some phenolic compounds in crocus sativus L. corms and its antioxidant activities study. Pharmacognosy Magazine, 7, 74-80. 
http://dx.doi.org/10.4103/0973-1296.75906

Esquivel, O. O., Moreno, A. O., Álvarez, V. B., Álvarez, L. D., \& Giusti, M. M. (2011). Phenolics, betacyanins and antioxidant activity in opuntia joconostle fruits. Food Research International, 44, 2160-2168. http://dx.doi.org/10.1016/j.foodres.2011.02.011

Fu, L., Xu, B. T., Xu, X. R., Gan, R. Y., Zhang, Y., Xia, E. Q., \& Li, H. B. (2011). Antioxidant capacities and total phenolic contents of 62 fruits. Food Chemistry, 129, 345-350. http://dx.doi.org/10.1016/j.foodchem.2011.04.079

Goh, S. H., Yusoff, F. M., \& Loh, S. P. (2010). A Comparison of the antioxidant properties and total phenolic content in a diatom, chaetoceros sp. and a green microalga, nannochloropsis sp. Journal of Agricultural Science, 2, 123-130.

Gursoy, N., Sarikurkcu, C., cengiz, M., \& Solak, M. H. (2009). Antioxidant activities, metal contents, total phenolics and flavonoids of seven morchell species. Food and Chemical Toxicology, 47, 2381-2388. http://dx.doi.org/10.1016/j.fct.2009.06.032

Hadizadeh, F., Khalili, N., Hosseinzadeh, H., \& Khair-Aldine, R. (2003). Kaempferol from saffron petals. Iranian Journal of Pharmaceutical Research, 2, 251-252.

Kafi, M., Kakhki, A. H., \& Karbasi, A. (2000). Saffron (crocus sativus) Production and Processing: Historical Background, Economy, Acreage, Production, Yield and Uses. Science Publisher, Enfield.

Karimi, E., Oskoueian, E., Hendra, R., \& Jaafar, H. Z. E. (2010). Evaluation of crocus sativus L. stigma phenolic and flavonoid compounds and its antioxidant activity. Molecules, 15, 6244-6256. http://dx.doi.org/10.3390/molecules15096244

Konczak, I., Zabaras, D., Dunstan, M., \& Aguas, P. (2010). Antioxidant capacity and phenolic compounds in commercially grown native australian herbs and spices. Food Chemistry, 122, 260-266. http://dx.doi.org/10.1016/j.foodchem.2010.03.004

Kosar, M., Goger, F., \& Baser, K. H. C. (2011). In vitro antioxidant properties and phenolic composition of salvia halophila hedge from turkey. Food Chemistry, 129, 374-379. http://dx.doi.org/10.1016/j.foodchem.2011.04.086

Lee, O. H., \& Lee, B. Y. (2010). Antioxidant and antimicrobial activities of individual and combined phenolics in olea europaea leaf extract. Bioresource Technology, 101, 3751-3754. http://dx.doi.org/10.1016/j.biortech.2009.12.052

Maksimovic, Z. (2008). In vitro antioxidant activity of ragweed (ambrosia artemisiifolia L., asteraceae) herb. Industrial Crops and Products, 28, 356-360. http://dx.doi.org/10.1016/j.indcrop.2008.04.001

Melnyk, J. P., Wang, S., \& Marcone, M. F. (2010). Chemical and biological properties of the world's most expensive spice: saffron. Food Research International, 43, 1981-1989. http://dx.doi.org/10.1016/j.foodres.2010.07.033

Negro, C., Tommasi, L., \& Miceli, A. (2003). Phenolic compounds and antioxidant activity from red grape marc extracts. Bioresource Technology, 87, 41-44. http://dx.doi.org/10.1016/S0960-8524(02)00202-X

Ordoudi, S. A., Befani, C. D., Nenadis, N., Koliakos, G. G., \& Tsimidou, M. Z. (2009). Further examination of antiradical properties of crocus sativus stigmas extract rich in crocins. Journal of Agricultural and Food Chemistry, 57, 3080-3086. http://dx.doi.org/10.1021/jf804041g

Pinelo, M., Rubilar, M., Sineiro, J., \& Nunez, M. J. (2004). Extraction of antioxidant phenolics from almond hulls (prunus amygdalus) and pine sawdust (pinus pinaster). Food Chemistry, 85, 267-273. http://dx.doi.org/10.1016/j.foodchem.2003.06.020

Rockenbach, I. I., Rodrigues, E., Gonzaga, L. V., Caliari, V., Genovese, M. I., Gonçalves A. E. S. S., \& Fett, R. (2011). Phenolic compounds content and antioxidant activity in pomace from selected red grapes (vitis vinifera L. and vitis labrusca L.) widely produced in Brazil. Food Chemistry, 127, 174-179. http://dx.doi.org/10.1016/j.foodchem.2010.12.137

Singh, R. P., Murthy, K. N. C., \& Jayaprakasha, G. K. (2002). Studies on the antioxidant activity of pomegranate (punica granatum) peel and seed extracts using in vitro models. Journal of Agricultural and Food Chemistry, 50, 81-86.

Temerdashev, Z. A., Frolova, N. A., \& Kolychev, I. A. (2011). Determination of phenolic compounds in 
medicinal herbs by reversed phase HPLC. Journal of Analytical Chemistry, 66, 407-414. http://dx.doi.org/10.1134/S1061934811040150

Termentzi, A., \& Kokkalou, E. (2008). LC-DAD-MS (ESI+) analysis and antioxidant capacity of crocus sativus petal extracts. Planta Medica, 74, 573-581. http://dx.doi.org/10.1055/s-2008-1074498

Winterhalter, P., \& Straubinger, M. (2000). Saffron-renewed interest in an ancient spice, Food Reviews International, 16, 39-59. http://dx.doi.org/10.1081/FRI-100100281

Wojdyło, A., Oszmianski, J., \& Czemerys, R. (2007). Antioxidant activity and phenolic compounds in 32 selected herbs. Food Chemistry, 105, 940-949. http://dx.doi.org/10.1016/j.foodchem.2007.04.038

Zhu, K. X., Lian, C. X., Guo, X. N., Peng, W., \& Zhou, H. M. (2011). Antioxidant activities and total phenolic contents of various extracts from defatted wheat germ. Food Chemistry, 126, 1122-1126. http://dx.doi.org/10.1016/j.foodchem.2010.11.144 